\title{
Efek Olahraga terhadap Kejadian Dismenor Primer pada Siswi Kelas X SMA Negeri 78 Jakarta Barat
}

\author{
Effect Exercise on Primer Dysmenorrhea Among Student \\ Class X SMA Negeri 78 West Jakarta \\ Nauri Anggita Temesvari*, Loli Adriani, Witri Zuama Qomarania \\ Fakultas Ilmu-Ilmu Kesehatan Universitas Esa Unggul \\ ('nauri@esaunggul.ac.id, 081382139012)
}

\begin{abstract}
ABSTRAK
Prevalensi dismenor banyak dialami oleh remaja. Studi menunjukkan bahwa wanita yang berolahraga memiliki proporsi yang lebih kecil untuk mengalami kejadian dismenor. Berdasarkan hal tersebut peneliti ingin melihat efek olahraga terhadap kejadian dismenor primer pada siswi kelas X SMA Negeri 78 Jakarta Barat tahun ajaran 2017/2018, dimana riwayat keluarga, lama menstruasi, usia menarkhe, stres, kebiasaan minum kopi, keterpaparan asap rokok, dan konsumsi alkohol yang dicurigai juga berpengaruh terhadap dismenor dikontrol. Untuk mencapai tujuan tersebut, maka penelitian ini menggunakan metode analitik dengan desain studi kasus kontrol. Disain studi kasus kontrol dipilih untuk melihat hubungan antara variabel faktor dan variabel outcome. Besarnya sampel minimal yang dipergunakan dalam penelitian kasus kontrol ini dihitung berdasarkan uji hipotesis beda proporsi sehingga didapatkan jumlah sampel kasus dan kontrol masing-masing 84 siswi. Dari hasil analisis bivariat didapatkan bahwa konsumsi alkohol dan kebiasaan olahraga berhubungan dengan dismenor primer (p-value <0.05). Dari hasil multivariat setelah mengontrol riwayat keluarga, lama menstruasi, usia menarkhe, stres, kebiasaan minum kopi, keterpaparan asap rokok, dan konsumsi alkohol didapatkan bahwa kebiasaan olahraga berpengaruh terhadap dismenor primer dengan p-value 0.043 dan OR 1.937 (95\% CI:1.021-3.672). Hasil tersebut menunjukkan bahwa kurangnya kebiasaan olahraga memiliki peluang 1.937 kali untuk menimbulkan dismenor primer.
\end{abstract}

Kata kunci : Dismenor primer, efek olahraga, siswi SMA

\section{ABSTRACT}

The prevalence of dysmenorrhea is mostly experienced by teenagers. Study showed that woman who did exercise had less proportion to feel dysmenorrhea. For that reason, this research purpose to analyze effect exercise on primary dysmenorrhea among student grade $10^{\text {th }}$ in SMA Negeri 78 Jakarta Barat, which family historical menstruation pain, menstruation period, menarche, stress, coffee consumption, smoke exposure, and alcohol consumption was controlled. To reach that purpose, the research used analysis method with case control study. The minimum sample size used in this case-control study was calculated based on the hypothesis testing of different proportions so that we obtained a total sample of cases and controls of 84 female students. Bivariate analysis showed alcohol consumption and exercise had related to primary dysmenorrhea ( $p$-value $<0.05)$. After controlled some variables, multivariate analysis showed exercise had effected to primary dysmenorrhea with p-value 0.043 and OR 1.937 (95\% CI: 1.124 - 3.913). The result showed lack of exercise had a chance 1.937 times to feel primary dysmenorrhea.

Keywords : Primary dysmenorrhea, exercise effect, senior high school student 


\section{PENDAHULUAN}

Dismenor dapat diartikan sebagai nyeri saat menstrusi. ${ }^{1}$ Dismenor dibedakan menjadi dismenor primer dan dismenor sekunder. Dismenor primer yaitu nyeri yang mucul dengan anatomi pelvis normal. Sedangkan dismenor sekunder terjadi karena proses patologis, sepertiendometriosis, adenomiosis, penyakit radang panggul, stenosis servikal, mioma atau polip uteri., ${ }^{2,3}$ Gejala pada dismenor primer adalah nyeri pada abdomen bagian bawah yang mulai muncul beberapa jam sebelum atau bersamaan dengan mulainya menstruasi. ${ }^{4}$ Angka kejadian dismenor di Indonesia sebesar $64,25 \%$ yang terdiri dari $54,89 \%$ dismenor primer dan $9,36 \%$ dismenor sekunder. ${ }^{5}$

Studi peninjauan sistematis di negara-negara berkembang menemukan bahwa $25-50 \%$ wanita dewasa dan sekitar $75 \%$ dari remaja mengalami sensasi nyeri selama menstruasi, dengan $5-20 \%$ dilaporkan mengalami dismenor berat atau menghambat mereka dari berpartisipasi dalam aktivitas sehari-hari. ${ }^{6}$ Pada penelitian di Surabayamenunjukkan bahwa dismenor primer dialami oleh $60-75 \%$ wanita muda.

Hasil survei yang dilakukan di Amerika Serikat pada tahun 2007, prevalensi dismenor diperkirakan $45-90 \%$. Nyeri haid mengakibatkan ketidaknyamanan dalam aktivitas keseharian. Ketidaknyamanan berhubungan dengan ketidakhadiran berulang di sekolah atau di tempat kerja, sehingga mengganggu produktivitas. ${ }^{8}$ Hasil penelitian di SMK Batik 1 Surakarta pada tahun 2010 juga menunjukkan bahwa dismenor terbukti berpengaruh terhadap penurunan aktifitas fisik. ${ }^{9}$

Studi menunjukkan bahwa wanita yang berolahraga memiliki proporsi yang lebih kecil untuk mengalami kejadian dismenor. ${ }^{10}$ Wanita yang berolahraga sekurang-kurangnya satu kali seminggu dapat menurunkan intensitas rasa nyeri dan ketidaknyamanan pada bagian bawah abdominal. Hal ini diprediksi karena endorphin yang dilepaskan di sirkulasi selama olahraga. Tampaknya secara umum dipercayai bahwa olahraga dapat mengurangkan gejala dismenor.

Pada penelitian lain di Turki oleh Unsal diperoleh prevalensi mahasiswi yang mengalami dismenor sebesar $72.7 \%$, dan diketahui bahwa konsumsi kopi, lama menstruasi, dan riwayat keluarga menjadi faktor risiko terjadinya dis- menor. ${ }^{3}$ Studi kohort yang dilakukan Chen, Cho, Damokosh, Chen, Li, Wang, dan $\mathrm{Xu}$, menunjukkan bahwa asap rokok berhubungan dengan kejadian dismenor. ${ }^{11}$ Pada penelitian Nahla juga mengatakan bahwa status gizi, usia menarkhe, lama menstruasi, dan riwayat dismenor pada keluarga berpengaruh terhadap kejadian dismenor primer. ${ }^{12}$ Selain itu, penelitian juga menunjukkan bahwa stres juga berpengaruh terhadap kejadian dismenor. ${ }^{13}$

Berdasarkan hal tersebut peneliti ingin melihat efek olahraga terhadap kejadian dismenor primer pada siswi kelas X SMA Negeri 78 Jakarta Barat tahun ajaran 2017/2018, dimana riwayat keluarga, lama menstruasi, usia menarkhe, stres, kebiasaan minum kopi, keterpaparan asap rokok, dan konsumsi alkohol yang dicurigai juga berpengaruh terhadap dismenor dikontrol. Kebiasaan olahraga dijadikan sebagai variabel utama agar hasil penelitian ini fokus ke pengaruh olahraga, sehingga hasilnya diharapkan dapat menumbuhkan motivasi pembaca untuk giat berolahraga. Pemilihan subjek penelitian diasumsikan bahwa siswi kelas X SMA Negeri 78 Jakarta Barat masih berada pada usia muda dan reproduktif, serta memiliki semangat yang tinggi dalam mencoba hal baru. SMA tersebut juga menyediakan sarana olahraga dan memiliki berbagai esktrakurikuler di bidang olah raga. Oleh karena itu, sekolah ini dianggap sesuai untuk melihat efek olah raga terhadap dismenor.

\section{BAHAN DAN METODE}

Penelitian ini dilakukan dengan metode analitik dan menggunakan desain studi kasus kontrol. Disain studi kasus kontrol dipilih untuk melihat hubungan antara variabel faktor dan variabel outcome. Variabel kebiasaan olahraga sebagai faktor risiko utama, karena sesuai dengan tujuan penelitian ini peneliti ingin melihat seberapa besar efek kebiasaan olahraga terhadap kejadian dismenor primer, dengan mengontrol dan mempertimbangkan riwayat keluarga, lama menstruasi, usia menarkhe, stres, kebiasaan minum kopi, keterpaparan asap rokok, dan konsumsi alkohol. Penelitian ini dilakukan di SMA Negeri 78, yang berada di Jakarta Barat, Provinsi DKI Jakarta. Subjek penelitian diasumsikan bahwa siswi kelas X SMA Negeri 78 masih berada pada usia muda dan reproduktif. Pemilihan sampel penelitian ini 
dilakukan dengan metode systematic random sampling. Besarnya sampel minimal yang dipergunakan dalam penelitian kasus kontrol ini dihitung berdasarkan rumus penentuan besar sampel untuk uji hipotesis beda proporsi. Berdasarkan perhitungan rumus besar sampel tersebut maka didapat jumlah minimum sampel untuk masing-masing sampel kasus maupun kontrol adalah sebanyak 78 siswa, dibulatkan menjadi 84 siswi.

Tahapan selanjutnya setelah proses pengolahan data yaitu analisis data. Hasil penelitian ini diperoleh melalui tiga jenis analisis, yaitu analisis univariat, biavariat menggunakan uji chi square, dan multivariat menggunakan regresi logistik. Analisis bivariat digunakan untuk melihat proporsi faktor utama (kebiasaan olahraga) dan variabel pengontrol lain, di masing-masing kelompok data, yaitu data kasus (mengalami dismenor primer) dan data kontrol (tidak mengalami dismenor primer). Analisis multivariat bertujuan untuk melihat besar efek kebiasaan olahraga, dengan mengontrol beberapa variabel lainnya. Analisis ini dilakukan dengan beberapa tahap, yaitu seleksi bivariat dan uji confounding.

\section{HASIL}

Responden pada penelitian ini berjumlah 168 siswi kelas X SMAN 78 tersebar dari kelas X MIPA A-G dan X BB. Rata-rata usia responden adalah 15 tahun. Usia menarche pada siswi paling banyak pada kategori 12-14 tahun sebanyak 123 siswi (73.2\%). Indeks Masa Tubuh (IMT) siswi paling banyak pada kategori normal sebanyak 103 siswi (61.3\%). 97 siswi (58\%) menyatakan kurang melakukan kebiasaan olahraga. Sebanyak 106 siswi (63.1\%) siswi menyatakan mengalami stress berat. Sebanyak 121 siswi $(72 \%)$ menyatakan tidak mengonsumsi kopi. Sebanyak 164 siswi (97.6\%) menyatakan tidak mengonsumsi alkohol. Sebanyak 168 siswi $(100 \%)$ menyatakan tidak melakukan kebiasaan rokok. Sebanyak 136 siswi (81\%) menyatakan tidak memiliki riwayat keluarga dismenor. Sebanyak 138 siswi (82.1\%) siswi mengalami lama menstruasi normal (Tabel 1).

Dari 84 siswi yang mengalami dismenor primer 60 siswi (71.4\%) menyatakan mengalami menarkhe pada usia 12-14 tahun, tidak memiliki riwayat keluarga dismenor sebanyak 67 siswi

\section{Tabel 1. Karakteristik Responden}

\begin{tabular}{|c|c|c|}
\hline Karakteristik & $n=168$ & $\%$ \\
\hline \multicolumn{3}{|l|}{ Kelas } \\
\hline X BB & 24 & 14.3 \\
\hline X MIPA-A & 19 & 11.3 \\
\hline X MIPA-B & 20 & 11.9 \\
\hline X MIPA-C & 18 & 10.7 \\
\hline X MIPA-D & 19 & 11.3 \\
\hline X MIPA-E & 13 & 7.7 \\
\hline X MIPA-F & 19 & 11.3 \\
\hline X MIPA-G & 17 & 10.1 \\
\hline X MIPA-H & 19 & 11.3 \\
\hline \multicolumn{3}{|l|}{ IMT } \\
\hline Normal $\left(18-25 \mathrm{~kg} / \mathrm{m}^{2}\right)$ & 103 & 61.3 \\
\hline Tidak Normal $(<18,5$ dan $>25)$ & 65 & 38,7 \\
\hline \multicolumn{3}{|l|}{ Stress } \\
\hline Ringan & 62 & 36,9 \\
\hline Berat & 106 & 63,1 \\
\hline \multicolumn{3}{|l|}{ Usia Menarche } \\
\hline$<12$ tahun & 44 & 26.2 \\
\hline 12-14 tahun & 123 & 73.2 \\
\hline$>14$ tahun & 1 & 0.6 \\
\hline \multicolumn{3}{|l|}{ Konsumsi Kopi } \\
\hline Ya & 47 & 28 \\
\hline Tidak & 121 & 72 \\
\hline \multicolumn{3}{|l|}{ Konsumsi Alkohol } \\
\hline Ya & 4 & 2.4 \\
\hline Tidak & 164 & 97.6 \\
\hline \multicolumn{3}{|l|}{ Konsumsi Rokok } \\
\hline Tidak & 100 & 100 \\
\hline \multicolumn{3}{|l|}{ Riwayat Ibu Dismenor } \\
\hline Ada & 32 & 19 \\
\hline Tidak & 136 & 81 \\
\hline \multicolumn{3}{|l|}{ Siklus Menstruasi } \\
\hline Teratur (21- 35 hari) & 127 & 76 \\
\hline $\begin{array}{l}\text { Tidak Teratur }(<21 \text { hari dan }> \\
35 \text { hari })\end{array}$ & 41 & 24 \\
\hline \multicolumn{3}{|l|}{ Lama Menstruasi } \\
\hline Normal (5-7 hari) & 138 & 82 \\
\hline $\begin{array}{l}\text { Tidak Normal }(<5 \text { hari dan } \\
>7 \text { hari })\end{array}$ & 30 & 18 \\
\hline \multicolumn{3}{|l|}{ Kebiasaan Olahraga } \\
\hline Ya & 71 & 42 \\
\hline Tidak & 97 & 58 \\
\hline \multicolumn{3}{|l|}{ Usia } \\
\hline Mean & \multicolumn{2}{|c|}{15.33} \\
\hline SD & \multirow{2}{*}{\multicolumn{2}{|c|}{0.542}} \\
\hline Minimal-Maksimal & & \\
\hline
\end{tabular}

(79.8\%), IMT normal sebanyak 51 orang $(60.7 \%)$, lama menstruasi normal sebanyak 69 siswi (82.1\%), dan tidak konsumsi kopi sebanyak 56 siswi (66.7\%), sedangkan siswi dismenor primer 
Tabel 2. Hasil Analisis Bivariat Variabel Penelitian

\begin{tabular}{|c|c|c|c|}
\hline \multirow[b]{2}{*}{ Karakteristik } & \multicolumn{2}{|c|}{ Dismenor Primer } & \multirow[b]{2}{*}{ p-value } \\
\hline & $\begin{array}{l}\text { Tidak } \\
\text { n (\%) }\end{array}$ & $\begin{array}{c}\text { Ya } \\
\text { n (\%) }\end{array}$ & \\
\hline \multicolumn{4}{|l|}{ IMT } \\
\hline Normal & $52(50.5)$ & $52(49.5)$ & 0.500 \\
\hline Tidak Normal & $32(49.2)$ & $32(50.8)$ & \\
\hline \multicolumn{4}{|l|}{ Stress } \\
\hline Ringan & $37(59.7)$ & $25(40.3)$ & 0.039 \\
\hline Berat & $47(44.3)$ & $59(55.7)$ & \\
\hline \multicolumn{4}{|l|}{ Usia Menarche } \\
\hline$<12$ tahun & $20(45.5)$ & $24(54.5)$ & 0.488 \\
\hline 12-14 tahun & $63(51.2)$ & $60(48.8)$ & \\
\hline$>14$ tahun & $1(100)$ & $0(0)$ & \\
\hline \multicolumn{4}{|l|}{ Konsumsi Kopi } \\
\hline Ya & $19(40.4)$ & $28(59.6)$ & 0.084 \\
\hline Tidak & $65(53.7)$ & $56(46.3)$ & \\
\hline \multicolumn{4}{|l|}{ Konsumsi Alkohol } \\
\hline Ya & $0(0)$ & $4(100)$ & 0.06 \\
\hline Tidak & $84(51.2)$ & $80(48.8)$ & \\
\hline \multicolumn{4}{|l|}{ Konsumsi Rokok } \\
\hline Tidak & $84(50)$ & $84(50)$ & $\infty$ \\
\hline \multicolumn{4}{|l|}{ Riwayat Ibu Dismenor } \\
\hline Ada & $15(46.9)$ & $17(53.1)$ & 0.422 \\
\hline Tidak & $69(50.7)$ & $67(49.3$ & \\
\hline \multicolumn{4}{|l|}{ Siklus Menstruasi } \\
\hline Teratur & $58(46)$ & $26(61.9)$ & 0.054 \\
\hline Tidak Teratur & $58(54)$ & $16(38.1)$ & \\
\hline \multicolumn{4}{|l|}{ Lama Menstruasi } \\
\hline Normal & $69(50)$ & $15(50)$ & 0.580 \\
\hline Tidak Normal & $69(50)$ & $15(50)$ & \\
\hline \multicolumn{4}{|l|}{ Kebiasaan Olahraga } \\
\hline Ya & $43(60.6)$ & $28(39.4)$ & 0.014 \\
\hline Tidak & $41(42.3)$ & $56(57.7)$ & \\
\hline
\end{tabular}

menyatakan mengalami stress sebanyak 59 siswi (70.2\%) dan kurang melakukan kebiasaan olahraga sebanyak 56 siswi (66.7\%).

Hasil bivariat menunjukan bahwa variabel yang behubungan dengan dismenor primer adalah kebiasaan olahraga (p-value 0.014) dan konsumsi alkohol(p-value 0.06). Sedangkan variabel lainnya menunjukkan tidak memiliki hubungan dengan dismenor primer (Tabel 2).

Selanjutnya dilakukan analisis multivariat dimana variabel IMT, stres, konsumsi kopi, konsumsi alkohol, menarkhe, riwayat keluarga dismenor, lama menstruasi yang tidak berhubungan terhadap dismenor primer ( $\mathrm{p}$-value $>0.05)$ dikeluarkan dalam model regresi. Setelah dikeluarkan variabel berdasarkan $\mathrm{p}$ value $>0.05$ dan pe- rubahan $\mathrm{OR}>10 \%$ mulai dari variabel dengan p-value paling tinggi yaitu konsumsi alkohol, riwayat dismenor keluarga, IMT, stres, dan konsumsi kopi. Hasil akhir menunjukan kebiasaan olahraga terbukti berpengaruh terhadap kejadian dismenor primer p-value 0.043 OR 1.937 (95\% CI: 1.021-3.672) (Tabel 3).

\section{PEMBAHASAN}

Siswi yang mengalami dismenor primer sebagian besar memiliki IMT normal. Hasil penelitian ini tidak sejalan dengan literatur yang menyebutkan bahwa kejadian dismenor berhubungan dengan status gizi seorang wanita. Pada wanita dengan IMT kurang dari berat normal dapat menjadi salah satu penyebab kurangnya daya 
Tabel 3. Hasil Akhir Pemodelan Regresi Faktor Berisiko terhadap Dismenor Primer pada Siswi Kelas X SMAN 78 Jakarta Barat

\begin{tabular}{lcccc}
\hline \multicolumn{1}{c}{ Variabel } & B & p value & OR & 95\% CI \\
\hline Kebiasaan Olahraga & 0.661 & 0.043 & 1.937 & $1.021-3.672$ \\
Konsumsi alkohol & 20.918 & 0.999 & 1214515356.404 & $0.000-\infty$ \\
Kebiasaan minum kopi & 0.486 & 0.196 & 1.594 & $0.786-3.234$ \\
Siklus Menstruasi & 0.511 & 0.172 & 1.667 & $0.801-3.470$ \\
\hline
\end{tabular}

tahan tubuh terhadap rasa nyeri sehinnga dapat terjadi dismenor. ${ }^{14}$

Pada penelitian ini menunjukkan bahwa siswi yang mengalami dismenor primer sebagian besar lama menstruasinya normal (5-7 hari) dan berdasarkan hasil uji statistik dapat diketahui bahwa lama menstruasi tidak berhubungan dengan dismenor primer. Hasil ini sejalan dengan penelitian Ammar yang menyatakan responden dismenor primer mengalami lama menstruasi yang normal. ${ }^{15}$

Usia menarkhe merupakan usia perempuan ketika mendapatkan menstruasi pertama kali. Pada umumnya menstruasi pertama terjadi pada usia 12 - 14 tahun. Namun, ada pula yang baru mendapatkan menstruasi pada usia lebih dari 16 tahun. Kecenderungan bahwa saat ini menarkhe terjadi pada usia yang lebih muda. Penerimaan remaja terhadap masa kematangan seksualnya bisa saja kurang baik karena belum siap dalam aspek psikis. Semakin muda usia perempuan mengalami menarkhe maka semakin belum siap juga untuk menerima menstruasi karena secara psikis hal tersebut dianggap sebagai gangguan atau reaksi kejutan (shock reaction) dalam tanggapan dan fantasi anak. Hasil penelitian menunjukkan bahwa responden yang mengalami dismenor primer sebagian besar mendapatkan menarkhe pada usia normal dan tidak ada hubungan antara usia menarkhe dengan kejadian dismenor primer.

Siswi yang dismenor primer tidak banyak mengkonsumsi kopi dan alkohol. Hal ini tidak sejalan dengan penelitian Chen yang menunjukkan bahwa kebiasaan merokok dan konsumsi alkohol memperbesar risiko dismenor. ${ }^{11}$

Siswi yang tidak mempunyai kebiasaan merokok juga mengalami dismenor primer. Penelitian menunjukkan bahwa kebiasaan merokok tidak berpengaruh terhadap kejadian dismenor primer. Hal ini sejalan dengan penelitian terdahulu bahwa perilaku merokok tidak ada hubungan dengan kejadian dismenor. Merokok dapat me- ngakibatkan nyeri saat haid karena di dalam rokok terdapat kandungan zat yang dapat memengaruhi metabolisme estrogen, sedangkan estrogen bertugas untuk mengatur proses haid dan kadar estrogen harus cukup di dalam tubuh. Apabila estrogen tidak tercukupi akibat adanya gangguan dari metabolismenya akan menyebabkan gangguan pula dalam alat reproduksi termasuk nyeri saat haid. ${ }^{16}$ Oleh karena itu, ada perbedaan hasil penelitian yang didapatkan dengan teori yang ada, bahwa orang yang tidak mempunyai kebiasaan merokok ternyata masih mengalami pula dismenor primer.

Siswi yang dismenor banyak yang menyatakan mengalami stress. Namun secara uji statistik tidak ada hubungan antara stres dan dismenor primer. Hal ini bisa disebabkan karena selain faktor stres/psikologi, ada faktor lain seperti ketidak seimbangan hormon prosgesteron dalam darah dan ketidakseimbangan hormon prostaglandin. Sebaiknya pengukuran tingkat stres dilakukan menjelang atau pada saat menstruasi awal agar hasil analisis hubungan antara keadaan stres dengan terjadinya dismenore primer bisa lebih tepat ${ }^{15}$

Siswi yang disemenor menyatakan tidak memiliki riwayat dismenor pada keluarganya. Hal ini berbeda dengan teori yang menyatakan riwayat keluarga merupakan faktor risiko yang dapat meningkatkan kemungkinan terjadinya dismenor primer. Dua dari tiga wanita yang menderita dismenor primer mempunyai riwayat dismenor primer pada keluarganya. Banyak remaja perempuan yang menderita dismenor primer dan sebelumnya mereka sudah diperingatkan oleh ibunya bahwa kemungkinan besar akan menderita dismenor primer juga seperti ibunya. ${ }^{17}$

Pada penelitian ini kebiasan olahraga berpengaruh secara signifikan terhadap dismenor primer. Kebiasaan olahraga merupakan kegiatan fisik/olah raga yang dilakukan responden meliputi 
senam, lari/joging, bersepeda, renang, jalan sehat. Olahraga secara teratur diyakini bermanfaat untuk mengurangi hiperplasia endometrium dan menurunkan produksi prostaglandin. Latihan fisik menyebabkan reseptor di dalam hipotalamus dan sistem limbik yang berfungsi untuk mengatur emosi menangkap hormon $\beta$-endorphin yang dapat dihasilkan setelah seseorang melakukan kebiasaan olahraga. ${ }^{18}$

Hasil penelitian terdahulu menunjukkan kesesuaian antara kejadian dismenor dakan meningkat jika kurang olahraga karena oksigen tidak dapat tersalurkan ke pembuluh-pembuluh darah di organ reproduksi yang saat ini terjadi vasokontriksi sehingga menyebabkab timbulnya rasa nyeri. ${ }^{19}$ Kebiasaan olahraga merupakan serangkaian aktivitas yang dilakukan secara terstruktur dengan berpedoman pada aturan tertentu yang tidak terikat pada intensitas dan waktunya. Olahraga yang dianjurkan adalah 3-4 kali tiap minggu dan setiap kali olahraga minimal 30 menit. $^{20}$

\section{KESIMPULAN DAN SARAN}

Siswi yang mengalami dismenor primer memiliki kebiasaan olahraga tidak teratur sebanyak 56 siswi (67.7\%). Hasil penelitian menunjukkan terdapat hubungan yang signifikan antara kebiasaan olahraga dengan kejadian dismenor primer (p-value $=0.020)$ dengan OR $2.098(95 \%$ CI: $1.124-3.913)$ yang artinya siswi yang tidak melakukan kebiasaan olahraga mempunyai peluang 2.098 kali mengalami kejadian dismenor primer. Setelah dilakukan kontrol terhadap beberapa variabel, kebiasaan olahraga terbukti berpengaruh terhadap kejadian dismenor primer p-value 0.043 OR 1.937 (95\% CI: 1.021-3.672). Rekomendasi dari penelitian ini adalah pihak sekolah mengembangkan konsultasi ke arah kesehatan reproduksi pada remaja dan pada mata pelajaran olahraga dilakukan pengukuran kondisi fisik secara regular seperti indeks masa tubuh.

\section{DAFTAR PUSTAKA}

1. Okoro R, Malgwi H, Ngong C, Okoro G. Dysmenorrhoea: Ways of Management among Nigerian University students. Actual Gyn. 2012;4:106-113.

2. Basel KA. Menstrual Disorders. Fam Med
Princ Pract. 2012;22(1):1369-1380.

3. Unsal A, Ayranci U, Tozun M, Arslan G, Calik E. Prevalence of Dysmenorrhea and its Effect on Quality of Life among a Group of Female University Students. Upsala Journal Medical Sciences. 2010;115(2):138-145.

4. Anisa MV. The Effect of Exercises on Primary Dysmenorrhea. Medical Journal Lampung University. 2015;4(2):60-65.

5. Nafiroh D, Indrawati ND. Gambaran Pengetahuan Remaja Tentang Dismenore pada Siswa Putri di MTS NU Mranggen Kabupaten Demak. Bidan Prada: Jurnal Ilmiah Kebidanan. 2013;4(2):157-166.

6. Harlow SD, Ephross SA. Epidemiology of Menstruation and Its Relevance to Women's Health. Epidemiologic Reviews. 1995;17(2):265-286.

7. Ningsih R, Setyowati, Rahmah H. Efektivitas Paket Pereda Nyeri pada Remaja dengan Dismenore. Jurnal Keperwatan Indonesia. 2013;16(2):67-76.

8. Haryanti RS. Hubungan Frekuensi Olahraga Aerobik dengan Kejadian Dismenore pada Remaja Putri. Profesi (Profesional Islam) Media Publikasi Penelitian. 2017;14(2):44-48.

9. Kurniawati D, Kusumati Y. Pengaruh Dismenore terhadap Aktivitas pada Siswi SMK. JurnalKesehatan Masyarakat.2011;6(2):93-99.

10. Bahri AA, Afriwardi, Yusrawati. Hubungan Antara Kebiasaan Olahraga dengan Dismenore pada Mahasiswi Pre-Klinik Program Studi Pendidikan Dokter Fakultas Kedokteran Universitas Andalas Tahun Ajaran 2012-2013. Jurnal Kesehatan Andalas. 2015;4(3):815821.

11. Chen C, Cho S II, Damokosh AI, et al. Prospective Study of Exposure to Environmental Tobacco Smoke and Dysmenorrhea. Environmental Health Perspectives. 2000;108(11):1019-1022.

12. Ibrahim NK, Alghamdi MS, Al-Shaibani AN, et al. Dysmenorrhea among Female Medical Students in King Abdulaziz University: Prevalence, Predictors and Outcome. Pakistan Journal Medical Sciences. 2015;31(6):1312-1317.

13. Fatmawati M, Riyanti E, Widjanarko B. Perilaku Remaja Putri dalam Mengatasi Dismenore (Studi Kasus pada Siswi SMK Negeri 
11 Semarang). Jurnal Kesehatan Masyarakat. 2016;4(3):1036-1043.

14. Larasati T, Alatas F. Dismenore Primer dan Faktor Risiko Dismenore Primer pada Remaja. Majority. 2016;5(3):79-84.

15. Ammar Ulya Rohima. Faktor Risiko Dismenore Primer pada Wanita Usia Subur di Kelurahan Ploso Kecamatan Tambaksari surabaya. Jurnal Berkala Epidemiologi. 2016;4(1):37-49.

16. YS Rifki, Ermawati E, Medison I. Hubungan Paparan Asap Rokok Lingkungan dengan Kejadian Dismenore Primer. Jurnal Kesehatan Andalas. 2016;5(3):590-594.

17. Coleman V. Persoalan Kewanitaan: Dari A
Sampai Z. Jakarta: ARCAN; 1991.

18. Pangkahila EA, Adiputra N, Pangkahila W, Yasa IWPS. Balanced Physical Exercise Increase Physical Fitness, Optimize Endorphin Levels, and Decrease Malondialdehyde Levels. Bali Medical Journal. 2016;5(3):145-148.

19. Idayanti T, Su'idah H, Haryanto DK, Sari SM, Mardiana HR, dkk. Influence of Dysmenorrhea Gymnastic on Menstrual Pain To $8^{\text {Th }}$ Grade Students of SMPN 2 Sooko District Mojokerto. International Journal Nursing Midwifery Science. 2018;2(1):12-19.

20. Brian J S. Kebugaran dan Kesehatan. Jakarta: Rajawali Pers; 2011. 